\title{
PHILOSOPHY AND COMMON SENSE
}

\section{by George Boas}

I should no doubt begin by defining what I mean by the two nouns in the title of this paper. But were I to do so, I should need a book rather than an essay in which to explain what I am talking about. For it is a tradition in philosophy to push matters back to their logical beginnings and that would be impossible within any reasonable number of words. Assuming then that we know what we are talking about-an admittedly shaky assumption-let me say that my purpose here is to suggest how philosophy is sometimes guided by common sense and how sometimes common sense is guided by philosophy.

We all grow up with a set of ideas, logical principles, rules for thinking, whose origin is more or less obscure. We do not invent our language but inherit it from others. But language, as is granted by almost everyone nowadays, is itself a sort of philosophy, concealing or expressing, according to one's views, a peculiar metaphysics. Professors of literature are accustomed to studying the special figures of speech which dominate certain writers and sometimes these figures of speech are common to a literary era. The lark that mounts to Heaven's gate is no invention of Shakespeare's nor are the twin pools which stand for eyes. But the prevalence of figures of speech need not be sought in literature. We all know how certain slang expressions arise, extend themselves through a social class, and then fade away. We also know how certain words come into fashion and then go out of fashion. I doubt very much whether such fashions express anything whatsoever beyond the desire for social conformity. One gains the esteem of one's social group by doing what they do, wearing the same kind of clothes as they wear, attending the same lectures, reading the same books, playing the same games, and naturally enough speaking the same speech. So at times certain types of philosophical problem come into fashion, at the present logical, linguistic, and aesthetic. As far as I know, no one is studying the problems of God, freedom, and immortality, which were of such importance to Kant. "No one" in this context means "very few," for there is always a survival from past eras which remains to plague the generaliser in cultural history. It is safe to say that historians of philosophy 
have become almost extinct, though there are still a few specimens left, about as many as there are of whooping cranes.

Linguistic style, if it is symptomatic of anything, indicates a state of mind, not a set of ideas in the sense that declarative sentences may be said to express ideas. But at the same time most of us do submit to the almost universal syntactical rules of the language which we are trying to speak and it is here that some writers have imagined that they could unearth a concealed philosophy. Thus in English and, as far as I know, in all Indo-European languages, we use common nouns and adjectives. These are obviously symbols for classes of things and events, not for individuals. They obviously select groups of beings and do not differentiate the members of the groups from one another. Moreover, in modern languages nouns and adjectives have no tenses, though in some Amerindian languages they do. When we say the noun house, we leave out all reference to when it existed or exists or will exist, and if we wish for some reason or other to bring in dates, we have to do so either by using a peculiar tense of the verb or by some adverbial phrase. We distinguish in this way between the temporal series and that which takes place in it, as we say. We do not integrate time into the being of things. This, I hope, is obvious.

Moreover, our common nouns and adjectives specify no location in space. And when we wish to indicate spatial situations, we again have to resort to adverbial qualifiers. In Japanese one says this-here-house, that-there-house, and that-house-way-over-there. But in English we talk as if the things of which we are speaking were unconditioned by their whereabouts or their dates, a house or a dog being just as domiciliary or canine wherever they may be found. Yet one classical theory of epistemology, that based on sensory data, overlooks the indisputable fact that location in time and space determines what one will perceive, even, in the case of vision, the traditional source of sensory data, determining size and shape. In this way by reflecting upon our language, at least upon one kind of language, we discover that we speak as if we believed that there are certain beings which are inherently spaceless and timeless. There is surely no need here to do more than say that the universals embodied in language are without individuality, though with specificity. They are related to particular things in time and space in a way that has never been satisfactorily explained except in the eyes of the explainer.

If it were possible to have a language in which all the words were particularized, so that one could not speak of a dog or a house, but only of, let us say, my-house-here-and-now, and if each of the verbal symbols were as different from what they are in English as the symbols, Abraham Lincoln or George Washington are different, then there could be 
no problem of universals since there would be no universals whatsoever. We do have a language which is composed exclusively of general terms, the language of mathematics, and I am told that very primitive languages are much more particularized than ours. If the symbol for my-yesterday-knife and my-today-knife do not both include the symbol for knife, there is little likelihood of anyone's abstracting either from the objects in question or from the perception of those objects any common property. But that does not mean that a person speaking such a language would not know what a knife was. In an antithetical case we use one word address both for the name of where one lives and for a speech, but we seldom, if ever, confuse the two. So, though we still differentiate amongst babies, adolescents, and adults, we nevertheless can recognize the personal identity of a human being at his various periods of life. The problem of universals does not arise in mathematics until someone tries to apply it within limits to the spatiotemporal world. The problem arises right out of the conflict between what we call experience and universals and what I am calling here common sense.

Common sense sets the problem here because we see a discrepancy between its data and those of theory. We are living in space and time and suddenly become aware of beings that do not appear to be spatiotemporal. We are confronted with particulars and suddenly discover that they exemplify in some mysterious manner universals. And if we say, as some philosophers have said, that we are also confronted with universals and actually come face to face with the nonspatial and nontemporal here and there and, it goes without saying, at precise moments of time, then we have to explain how a timeless being can intrude into the world of time and not take on a date. For such intrusions occur at certain moments. And if we say that universals are only words, then we have to explain why particulars obey the dictates of those words. We can call things anything we please, but whether we call something by a great variety of names or not, we have to recognize it as having certain persistent traits which it shares with other things. And our old problem is before us again. For how are we to describe the sharing of common properties without involving universals?

We are thus in the position of granting that here a philosophic problem arises out of common sense. But we also have to grant that we shall not be satisfied with any solution of the problem which cannot be verified by common sense. But if in considering the rise of the problem we mean linguistic usage by common sense, we surely do not mean that when we are talking of verification. If we are talking about linguistic usage, then clearly there is caninity as well as dogs. But though it may be argued that the problem of the reality of universals arises because we use such a word as "caninity," and define it in general terms, it is not 
solved by pointing to the word. Before we can answer this question we have to have criteria of reality and those criteria are not to be found in grammars and dictionaries. It is not in a course in English Composition that one learns that dreams, hallucinations, optical illusions, ghosts, and negative afterimages are unreal. Nor is it through any experience of this set of unrealities. We discover that something perceived is unreal by comparing it with something that is real, not by simply looking at it. For no experience by itself, isolated from the total mass of our memories, ever says anything about its own reality. Judgments of reality are made after the event. One has to stop to think before passing on the reality of any experience. Our illusions would not mislead us if they announced their illusory nature as soon as they appeared before us. It is because we already know so much that we are seldom misled by the common illusions of perception. No one by experience uncorrected by thinking could have announced that the earth moves round the sun. If then we say that the sun is really stationary, it is not because of simple visual experience. We are constantly correcting our experience by means of what we know of science and philosophy.

One set of these criteria is certainly reflected in and stimulated by language. I refer to our growing use of abstractions that accompanies step by step the spread of natural science. What has been called the science of envelops is an example of this. The word "envelop" is used to name those more inclusive terms that have to be used as, for instance, biology is absorbed into chemistry, chemistry into physics, physics into mathematics. But science also has evolved in the direction of more inclusive or general laws. The stock example of this is physics, which up to the time of Newton had two sets of laws, one for sublunary and another for superlunary motions. But similarly in chemistry, until 1828 when urea was synthesized, there had to be two sets of laws, one for inorganic and another for organic substance. If then the name of a thing is made to connote its most general traits, those which it shares with other things, scientific names will become as abstract as nonscientific and for the purposes of science such abstractions may become essential.

For when it is of interest to make deductions, one has to have general propositions. In logic it is a case of all or none; in science it may be a case of most or almost none. In order to attain generalities, one has obviously to overlook those traits which distinguish one thing from another, and hence one has to develop techniques for overlooking them. These techniques are those of the laboratory. Fortunately for the philosopher, laboratory conditions are set up deliberately and for stateable purposes; they do not simply occur. And most scientific laws, when accurately phrased, include the conditions under which they are true. If I am not being too cynical, I should say that laboratory conditions are the 
conditions under which scientific laws become true. Moreover, when an event of a recognizable type occurs outside of a laboratory, such as a brick falling off a roof, a scientist is supposed to be able to explain why the law is not strictly obeyed. His explanation consists in measuring the difference between laboratory and nonlaboratory conditions. As primitive observers we first see each object as an individual thing and our classifications are originally made by our parents, siblings, and friends. We learn what to call things, what their names are, and presumably these names were applied because certain characteristics were selected as most important. Why they were important is now undiscoverable, though sometimes one's imagination helps. We can perhaps discover why children call railroad trains choo-choos and dogs bow-wows. We can also imagine that things that are irrelevant to the interests and knowledge of daily life are all lumped together, as children lump all numbers over a few as "a lot." When scientists first classified material objects as earthy, aerial, aqueous, and fiery, we no longer know what was their motive. But it must have taken a tremendous expansion of the scientific imagination to think of all substances as combinations of four. And a similar expansion of the imagination must have been required for Aristotle to reduce the complexity still further by making heat and moisture primary, defining cold and dryness as the simple absence of their opposites. The theory of the four elements, which gave rise to one of the most harmonious and general of theories, lasted well into the eighteenth century and was a triumph of science and philosophy over common sense. But it too had to meet the challenge of common sense. Experience, whatever its high status in empirical philosophies, is always a challenge to a philosopher for it refuses to behave as philosophers say it should. The discrepancies between common sense observation and scientific theory always exist and there is no rule that has as yet been formulated for telling a man when he must correct one by the other.

Sometimes philosophy corrects common sense instead of subjecting itself to it. But again we have to ask in what the correction consists. No one can deny the data of the visual world. They are simply there and, though we can explain them, we cannot explain them away. The correction must not be of the type which attributes them to a diseased mind. And I think I am right in saying that it first consists in accepting the tangible and ponderable object as the real one and then showing the conditions under which it will change its visual shape and size. I have been told by physicists that one could start with visual objects as real and interpret the behavior of tangible and ponderable ones as deviations from the visual norm. But I have also been told that such a system would become too complicated to be tolerated. If this is so, the criterion of simplicity is of primordial importance and should be examined. When Osi- 
ander says, in his introduction to Copernicus' Revolutions of the Heavenly Spheres, that nature always follows the simplest course, he means apparently a course that can be described with as few presuppositions and indefinables as possible. If one can define an event as a function of two variables, one has discovered something simpler presumably than a course that can be defined only in terms of three variables. But who can deny that the simplicity herein is not so much nature's as ours? Again, when Locke defined the real objects of the world in terms of those properties which were sufficient, if not necessary, for the construction of Galilean physics, he too simplified nature in the sense of reducing the number of its properties and correlating all other observable properties with change in human observation. But Locke thought he knew that the mind could know only ideas and that knowledge was the organization of ideas. And since he flatly refused to examine the mechanism by which ideas arose in the mind, but limited himself to studying the ideas after they had arisen, he was able to avoid many of the puzzles which his successors became mired in.

If common sense were to intervene at this point, it would observe that by this act of Locke's, at least three levels of beings were established: (1) the level of the Galilean properties; (2) the level of sensory qualities; and (3) the level of images, hallucinations, dreams, and illusions. These levels seem to be established by the degree of commonness of what is perceived: the Galilean properties are available to all observers under definable conditions; the secondary qualities are detectible only when a human mind is one of the variables of which they are functions; the third level is observable only to a single person at a time. Students who have taken even elementary courses in the history of philosophy will remember how Berkeley and Hume reduced these levels to one. That one was what Hume called the shifting theater of perception, in which there was no reason to believe either in a perceiving mind or in any causal relations in the ordinary sense of that term. As far as I know, the reasoning to this position was accurate, granting the presuppositions, and if Hume had carried it on to what we-who have the advantage of living two centuries later than he-would call its logical conclusion, he would have ended with that purely theoretical philosophy known as the solipsism of the present moment.

The strange thing about this conclusion is that when we have reached it, as Santayana did in the first part of Scepticism and Animal Faith, we immediately try to escape from it. We have a curious and perhaps unjustified feeling that though logically sound, there must be something wrong with it. We ask how we can prove the existence of other people's minds, of the past and the future, of the wall behind our backs, of the chair in the room next door. Nor does it occur to us that if the 
position is sound, such questions ought not even to occur to us. Why should we have this curious feeling? In fact, we might even ask how we could say that only I exist at this moment, if we did not believe that there were other minds to be distinguished from ours, other times from which the present is set off? This feeling is surely not the result of any theoretical considerations; it comes straight out of common sense. Moreover, one can hardly avoid asking the source of the rules by which we reach this apparently unsatisfactory conclusion. If we engage in extrapolations of our present experience into the past and future and other regions of space, where does the technique of extrapolation itself come from? Surely not from immediate observation. When one sees a patch of red, one does not and cannot deny that he sees it. He raises questions about it only when he tries to say something about it which goes beyond its redness. But why should he feel constrained to go beyond its redness, if only to ask what it is that is red? Only, I suggest, because one of the undeniable and persistent traits of our experience, whether perceptual or not, is its temporal dimension. We can no more divest ourselves of what common sense calls our memory than we can of the colors, sounds, tastes, and textures that arise before us.

Philosophers are rational people who work themselves into corners, not by committing fallacies, but by avoiding them; that can be said in their praise. But once they have got themselves into a corner, they seem unwilling to remain there and look for all sorts of devices by means of which they can escape. This is quite unlike what other rational people usually do. When we are told, for instance, that white light is a combination of all the spectral colors, absurd as this seems to common sense, we accept it as true. And when we are told that solid objects consist largely of empty space, we swallow that also and do not try to prove that empty space is really full. When we see great oaks from little acorns growing, we may wonder how it is possible, but we do not deny its possibility. And if someone were to maintain that great oaks could also grow from gloxinia seeds, and proved it by rigidly controlled experiments, repeating them in the traditional way, botanists would have to sigh and admit that it was true. Only intellectual Tories would insist that in reality the acorn was the real oak seed and that the oaks which grew out of the gloxinia seeds were illusions. It must not be denied that such intellectual Tories have existed-the history of the Copernican theory, of evolutionism, of the mechanical theory of heat, of indeed almost all scientific theories is evidence enough of the reluctance of the human race to accept the evidence for novelty. But sooner or later, unless such theories are disproved, and let us omit a discussion of what the disproof of a scientific theory consists in, they win out and are taught in textbooks as commonly accepted opinions. But no one to speak of ever accepted 
solipsism seriously in spite of the fact that no one could find a flaw in the argument leading to it.

When philosophers like Santayana introduce something called animal faith as a basis for our belief in those things for which we have no rational evidence, they say no more than if they had simply introduced common sense. Of course we believe in other people's minds, the room next door, a world of external objects, and all the rest. Without indulging in any intellectual tricks, let me say that whether one calls this kind of belief common sense or not, is a matter of indifference. What is not a matter of indifference is that there exists a set of beliefs which we have to justify and that it is not a set which we reach through demonstration, reasoning, experimentation, or revelation. This set of beliefs can be phrased as a set of propositions which do not demand proof and which act as the criteria of satisfactory theorizing. By this I mean that I do not have to prove the existence of the past or of the other things of whose existence certain epistemological theories raise doubts, unless we have already reached the conclusions that they do not exist. If I conclude that there is no past or no external world, I have the choice of going no further or of going back and trying to discover where my reasoning went astray. But the suspicion that my reasoning did go astray is what is of interest. It could not have happened because of the train of thought which led to the unsatisfactory conclusions, for if it had, I might have caught it in the act. I have obviously accepted a set of ideas as standard truths and use them to check my reasoning. We might be expected to say in philosophy that if we come out with no external world, no past, no future, no distant space, and so on, we have either committed an error in reasoning or that common sense has been in error. No proof is needed that frequently common sense has indeed been erroneous. To common sense the earth is flat, the sun moves through the skies from east to west, the moon waxes and wanes, and eels are generated from horsehairs. It might be expected to be wrong here too.

There are only two ways of critically examining an argument. One is to look at the premises and see whether they are acceptable or not; the other to look at the reasoning and see whether it is fallacious. I am assuming here, with most of my colleagues, that the reasoning of the solipsist is correct. We must therefore turn to the premises. And if the conclusions are to be tested by their harmony with common sense, then it might be expected that the premises would be similarly tested. If we want to prove that there is a room next door, we had best choose premises which will not make it impossible to do so. Among those premises must be the criteria by means of which we can tell whether a room exists or not. If we want to know what flag is flying from the mast of a ship, we must know what certain flags look like before we guess. And 
we must know this before we make our guess. That knowledge could not possibly arise out of the immediate data of sense. But if we grant this, we have to grant also that knowledge or, if you prefer, belief, has a history in everyman's biography.

Questions of this sort often arise because of the discrepancy between what we are seeing and what we expected to see. If we see a ship with the flag flying upside down, we cannot tell what it signifies unless we know the code. And I venture to say that it is not the sight of the flag upside down that raises the question in our minds but the expectation that it ought to be flying rightside up. The perceptual data in themselves are utterly inarticulate until they have been interpolated into a larger set of data which have been previously interpreted or given conventional significance. They are made to "say" something when their appearance can be inferred from other things as a rule, but no rule can be established on the single occurrence of any set of data, however complicated. There must be a long series of repeated events for the establishment of rules and no one can be confident that he has the right rule unless his experience is corroborated by that of other people. For just as our language assumes the existence of time and of other people's minds, so do our processes of verification.

The question of whether the sensory data are subjective or objective is irrelevant to the truth of knowledge in the sense of judgment. All that is required is that they occur in a regular and predictable manner. All that the scientific investigations of their origin proves is that they are functions of two variables: material stimuli, causes, sources, what you will, in the nonhuman world, and the whole perceptual apparatus of human beings. Neither alone will suffice. But if we are talking about knowledge in the sense of assertions or judgments, the sensory data become both the criteria of truth and error, and also the stimuli to questions. But both as criteria and as stimuli to questions, they are just dumb things when isolated from human interests. A single color, red, may be evidence of a large variety of statements and similarly a combination of sensory data may be required to prove a single simple statement. It takes but a few moments' reflection to show that there is no possibility of making a one-to-one correspondence between sensory data and all possible judgments.

To save space I shall say nothing of certain other metaphysical aspects of Indo-European languages, such as those involved in the subjectpredicate proposition, the necessity of subjects for verbs, and the reification of processes. It is more important to emphasize something which is not inherently linguistic, the social element in knowledge. We demand that all truths be interpersonal. Just as we assume that anyone with the proper training can repeat someone else's experiments, and that no ex- 
periment can be accepted until it has been repeated, so we assume that any belief must be corroborated by others if we are to accept it. That there is such a thing as what used to be called an inner life is no doubt true, but it is of little use so long as it cannot be communicated. Such experiences as religious conversions, the beatific vision, the delusions of the mentally diseased, are of course experienced by only one person at a time. They clearly are no more interpersonal than a toothache. But what should concern the philosopher is not so much their privacy as the need their possessors feel of telling other people about them. The writing of lyric poetry, for instance, has the paradoxical factor of exteriorizing, as the French say, that which is internal. The situation suggests that we do not trust our own direct experience until it is shared by another. The anguish which is felt when the attempt at communication fails to reach its end is characteristic of the situation. It is as if one felt that experience must be shared or remain illusory. Thus common sense assumes without question not only the existence of other minds, but their function as witnesses to the truth of anybody's opinions.

I make no claim to having done anything more than state a problem. Common sense creates problems for the philosopher and also answers them. The many mansions of religion will have to be granted a place in philosophy as well. But to the man whom this volume is supposed to honor, this will not prove embarrassing. 